\title{
ANTERIOR OPEN BITE CLOSURE: A CASE REPORT
}

\author{
Dr Deepak Sharma, ${ }^{1}$ Dr Hemant Kumar Halwai ${ }^{2}$ \\ $1,{ }^{2}$ Asst. Professor, Department of Orthodontics \\ UCMS -College of Dental Surgery, Bhairahawa, Nepal
}

E-mail: drhemanthalway@gmail.com

\section{ABSTRACT}

Anterior open bite is often caused by a downward rotation of the mandible and/or by excessive eruption of the posterior teeth. In such cases, it is difficult to establish absolute anchorage for molar intrusion by traditional orthodontic mechanics. This article reports the successful treatment of a severe skeletal anterior open bite case using titanium screw anchorage. A female patient of 31 years of age had open bite of $7 \mathrm{~mm}$ with increased facial height. The mini screws were implanted on both maxilla and the mandible, and an intrusion force was provided with elastic chains for 13 months. After active treatment of 19 months, her upper and lower first molars were intruded by about $3 \mathrm{~mm}$ each, and good occlusion was achieved. Her retrognathic chin and convex profiles were improved by an upward rotation of the mandible. Our result suggests that titanium screws are useful for intrusion of molars in anterior open bite cases.

\section{INTRODUCTION}

Skeletal anterior open bite is one of the most difficult cases to treat in orthodontics. In adult patients, treatment of severe skeletal anterior open bite mainly consists of surgically repositioning of the maxilla and the mandible. This is true because adults have little growth potential, and often open bites are combined with a longface tendency. ${ }^{1,2}$ However, there are cases when patients do not wish to undergo surgical treatment because of its risk factors. For such patients, various treatment alternatives include multibrackets in conjunction with high-pull headgear, extraction therapy, ${ }^{3,4}$ multiple-loop edgewise archwire (MEAW) technique, ${ }^{5}$ and archwire with intermaxillary elastics. ${ }^{6}$

These techniques may provide acceptable interincisal relationship and increased overbite. However, the skeletal improvements are often poor because it is difficult to establish absolute anchorage for molar intrusion by traditional orthodontic mechanics such as multibrackets combined with intra or extraoral anchorage. To obtain an absolute anchorage; dental implants, ${ }^{7-10}$ screws, ${ }^{11-13}$ and miniplates ${ }^{14-16}$ have been used as orthodontic anchorage. These materials can provide absolute anchorage for various tooth movements without substantial patient's cooperation.
There are reports of screws being used for anchorage in tooth movement, intrusion or retraction of anterior teeth, for protraction of lower molars, and for severe skeletal anterior open bites. In addition, there are reports of intrusion of molars in both maxilla and the mandible with absolute anchorage. The present case report demonstrates the usefulness of titanium screws for orthodontic anchorage to intrude the upper and lower molars of an adult patient with severe skeletal anterior open bite.

\section{CASE REPORT}

A 31 years old female patient reported with the chief complaints of chewing problem and anterior open bite. A convex profile due to retrognathic mandible was noted. An acute nasolabial angle, increased lower facial height, circumoral musculature strain on lip closure, and severe anterior open bite of $-7 \mathrm{~mm}$ was observed. In addition, two distinct occlusal planes were present in the upper arch. Crowding was present in the upper arch because of the constricted arch form. The upper dental midline almost coincided with the facial midline, but the lower dental midline did not coincide (Figure1).

The cephalometric analysis showed a skeletal Class I relationship (ANB 4.1) with mandibular retrusion (SNB 
73.2) (Figure 2). The mandibular plane angle was steep, and the Gonial angle was large (MP/FH 38.6, Go Angle 136.7). Mandibular body length and ramus height were within the normal range. The lower incisors were labially inclined (U1/ FH 128.2, L1-MP 96.4). Both upper and lower molars were significantly extruded (U6/NF 31.6, L6/MP 37.4).

The case was diagnosed as Angle's Class I malocclusion, skeletal Class I jaw base relation with skeletal anterior open bite. The treatment objectives were to correct anterior open bite thus to establish normal overjet and overbite, to achieve an acceptable occlusion with a good functional relation, and to correct the retrognathic appearance of the facial profile. The cause of the anterior open bite was suggested to have been extrusion of both upper and lower molars; therefore we planned to implant screws to use as anchorage to intrude both the upper and the lower molars.
Titanium screws (2.3 $\mathrm{mm}$ diameter, $14 \mathrm{~mm}$ length; Leone Italy) were inserted bilaterally on the zygomatic process of the maxilla and on the buccal alveolar bone of the mandible through the buccal mucosa (Figure 4). Screws were implanted under local anesthesia; analgesics and antibiotics were prescribed to the patients for 3 days after the implantation. A transpalatal arch appliance was placed between the first molars to compensate for the buccal crown torque that would occur due to the intrusive force (Figure 5). Then, the upper right first premolar and the left central incisor were extracted, and 0.022 inch slot preadjusted edgewise appliances were bonded on both arches. During the leveling phase, the lower left central incisor was extracted. After leveling and alignment with nickel-titanium archwires, 0.019 X 025 inch stainless steel archwires were placed, and retraction of the anterior teeth was begun.
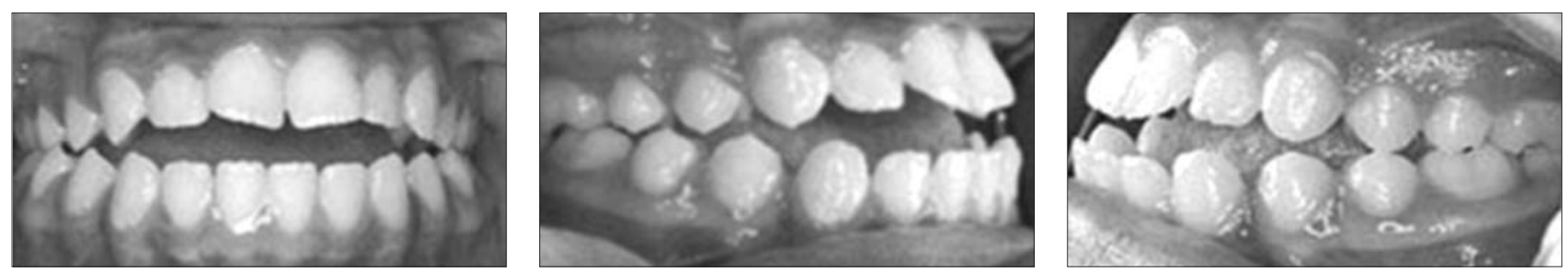

Fig 1. Pretreatment intra-oral photographs
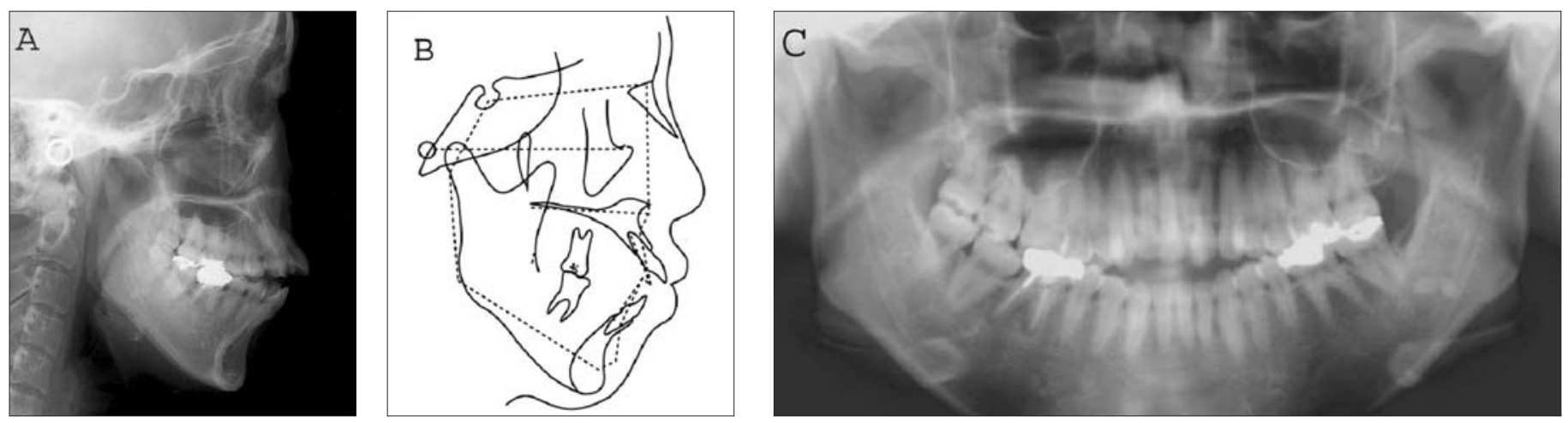

Fig 2. Pretreatment cephalograph and tracing; Tracing (solid lines) was superimposed with the mean profilogram (dotted line)
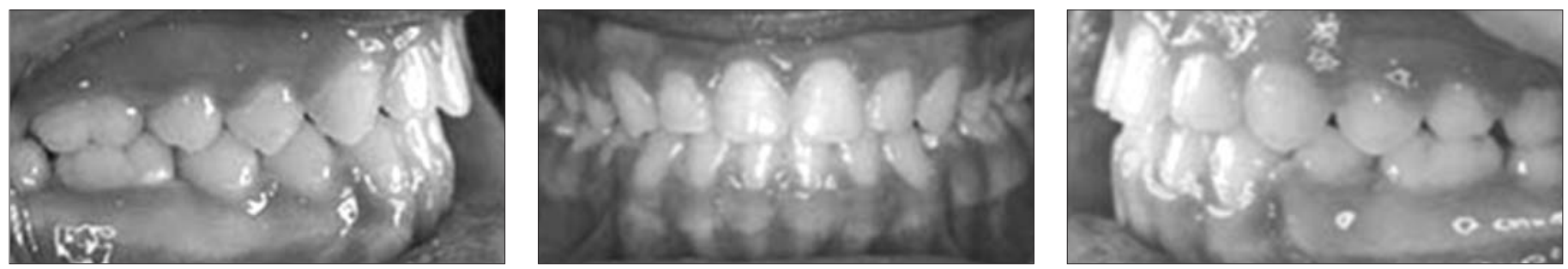

Fig 3. post treatment photographs 


\section{TREATMENT RESULT}

The post-treatment facial photographs showed a dramatic change in the facial profile when compared to pretreatment records. As a result of intrusion of the upper and lower molars, the mandible rotated counterclockwise, and the severe anterior open bite was improved. Rotation of the mandible caused advancement of the chin $8 \mathrm{~mm}$ at pogonion and improved the retrognathic appearance of the facial profile. The anterior facial height was significantly reduced, and straining of the circumoral musculature during lip closure disappeared. By preventing the anterior extrusion, an esthetic smile was achieved.
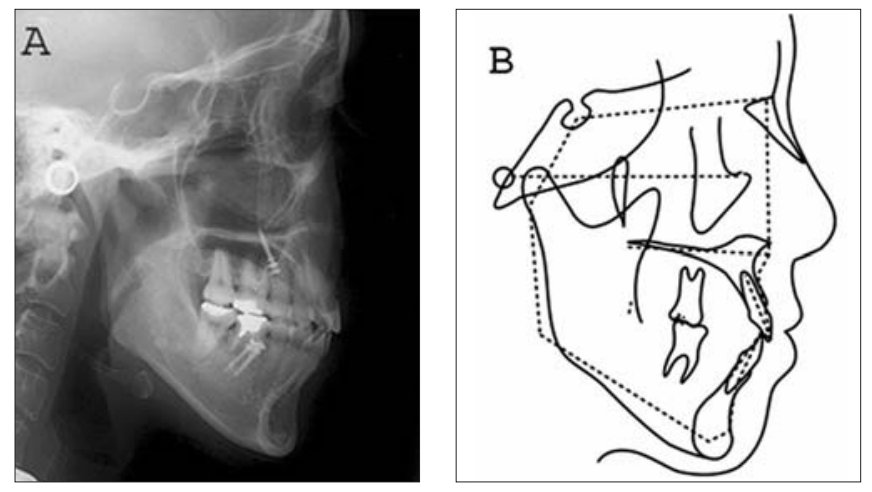

Fig. 4. (A) Postactive treatment cephalograph. (B) Tracing. (C) Panoramic radiograph. Tracing (solid lines) was superimposed with the mean profilogram (dotted line)

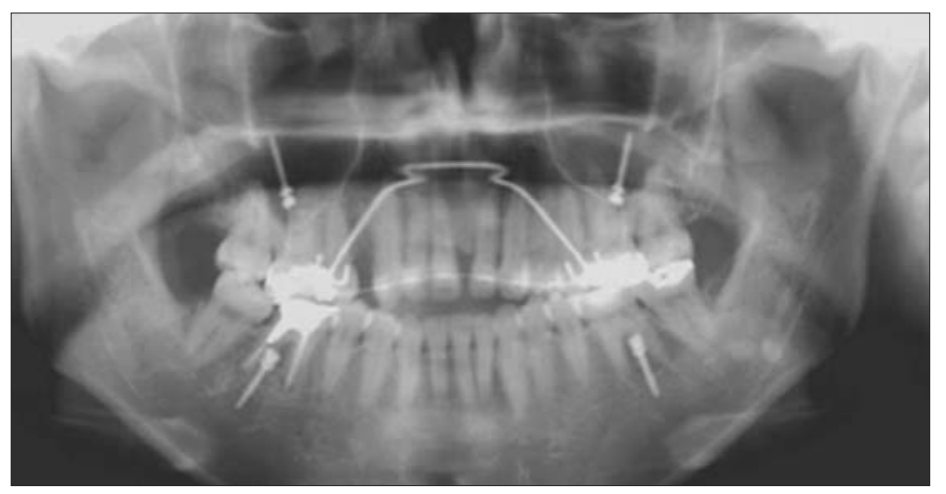

Fig 5. Panoramic radiograph after implantation of titanium screws

Table 1. Pre-treatment and post-treatment cephalometric analysis

\begin{tabular}{cccc}
\hline Parameter & Pre-treatment & Post-treatment & Difference \\
SNA & 77.3 & 77.0 & 0.3 \\
SNB & 73.2 & 75.8 & 2.6 \\
ANB & 4.1 & 1.2 & -2.9 \\
U1/NF & 33.1 & 35.4 & 2.3 \\
U6/NF & 31.6 & 28.8 & -2.8 \\
L1/MP & 50.2 & 47.6 & 2.7 \\
L6/MP & 37.4 & 34.8 & -2.7 \\
\hline
\end{tabular}




\section{DISCUSSION}

An anterior open bite is often caused by downward rotation of the jaws and/or excessive eruption of posterior teeth. For non-surgical treatment of these cases, MEAW is sometimes used. The cephalometric evaluation of patients treated with MEAW shows remarkable changes in the dentition, but the changes that occurred in the skeletal pattern were very small. Extrusion or compensatory eruption of the anterior teeth is often undesirable for the treatment of skeletal open-bite cases when combined with maxillary vertical excess and a long-face tendency. In the present case, the mandible was rotated downward, and the patient had a long-face tendency due to extrusion of both upper and lower molars. Therefore, we considered that absolute anchorage was required for intrusion of the molars.

Several methods to acquire skeletal anchorage have been reported. Dental implants are strong enough to resist the counteraction of orthodontic tooth movement, but they require complicated surgery for both placement and removal; furthermore they involve higher cost. Miniplates have also been used for orthodontic anchorage. ${ }^{14}$ In anterior openbite cases, two reports showed the usefulness of the miniplate as a skeletal anchorage and for closure of the bite without extrusion of the anterior teeth. ${ }^{15,16}$ However, miniplates have the disadvantage of surgical damage and risk requiring mucoperiosteal flap operation for both setting and removing them. ${ }^{16}$

In the present case, both upper and lower molars were extruded, and screws were placed on the posterior region of the jaws. However, the posterior part of the jaws tend to have a thinner, more porous cortex with finer trabeculae..$^{20.21}$
Therefore, the screws were placed on the zygomatic process of the maxilla. The mandible generally has a denser cortex and thicker trabeculae than the maxilla. However according to a recent study, high mandibular plane angle was found to be a risk factor for failure of screw-type implant anchors, and the diameter of the screw was significantly associated with its stability. ${ }^{18}$ In addition, it was reported that the buccal cortical bone in case of high mandibular plane angle was thinner than that in the case of low angle at lower first molar region. ${ }^{22}$ Therefore, titanium screws of $2.3 \mathrm{~mm}$ diameter and $14 \mathrm{~mm}$ length were placed for sufficient mechanical interdigitation as the mandibular plane angle was quite steep in this case. After the intrusion, the screws were retained until completion of active treatment to prevent possible relapse. After the retention phase, the screws were removed easily with the screwdriver.

In previous reports, the intrusion of molars in one jaw was quite effective for overbite correction, but the facial profile improvement was poor because unwanted extrusion of molars occurred in the opposite jaw. ${ }^{15.16}$ In the present case, we intruded both upper and lower molars, and as a result of this treatment, the mandible was significantly rotated in a counterclockwise direction, and major skeletal changes were achieved. Therefore, it is suggested that the intrusion of molars in both jaws is desirable in cases of severe anterior open bite caused by extrusion of the upper and lower molars. Our treatment results were acceptable and similar to those obtained by two-jaw orthognathic surgery, i.e. rotation of the mandible after impaction of the maxilla. ${ }^{23}$ Moreover treatment using implant anchorage is minimally invasive and requires a shorter treatment period than orthognathic surgery. Therefore, there is a possibility that this method will become an alternative to orthognathic surgery. 


\section{REFERENCES}

1. Epker, B. N. and L. C. Fish. Surgical-orthodontic collection of openbite deformity. Angle Orthod 1977; 71:278-299.

2. Proffit, W. R., C. Phillips, and C. Dann IV. . Who seeks surgical-orthodontic treatment? Int J Adult Orthod Orthognath Surg 1990; 5:153-160.

3. Alexander, C. D. Open bite, dental alveolar protrusion, Class I malocclusion: a successful treatment result. Am J Orthod Dentofacial Orthop 1999; 116:494-500.

4. Smith, G. A. Treatment of an adult with a severe anterior open bite and mutilated malocclusion without orthognathic surgery. Am J Orthod Dentofacial Orthop 1996; 110:682-687.

5. Kim, Y. H. Anterior open bite and its treatment with multiloop edgewise archwire. Angle Orthod 1987; 4:290-321.

6. Enacar, A., T. Ugur, and S. Toroglu . A method for correction of open bite. J Clin Orthod 1996; 30:43-48.

7. Turley, P. K., C. Kean, J. Schur, J. Stefanac, J. Gray, J. Hennes, and L. C. Poon. Orthodontic force application to titanium endosseous implants. Angle Orthod 1988; 58:151-162.

8. Ödman, J., U. Lekholm, T. Jemt, P-I. Brånemark, and B. Thilander. Osseointegrated titanium implants: A new approach in orthodontic treatment. Eur J Orthod 1988; 10:98-105.

9. Prosterman, B., L. Prosterman, R. Fisher and M. Gornitsky. The use of implants for orthodontic correction of an open bite. Am J Orthod Dentofacial Orthop 1995; 107:245-250.

10. Roberts, W. E., F. R. Helm, K. J. Marshall, and R. K. Gongloff. Rigid endosseous implants for orthodontic and orthopedic anchorage. Angle Orthod 1989; 59:247-256.

11. Creekmore, T. D. and M. K. Eklund. The possibility of skeletal anchorage. J Clin Orthod 1983; 17:266-269.

12. Costa, A., M. Raffaini, and B. Melsen. Miniscrews as orthodontic anchorage: A preliminary report. Int J Adult Orthod Orthognath Surg 1998; 3:201-209.

13. Park, H. S., S. M. Bae, H. M. Kyung, and J. H. Sung. Micro-implant anchorage for treatment of skeletal Class I bialveolar protrusion. J Clin Orthod 2001; 35:417-422.

14. Jenner, J. D. and B. N. Fitzpatrick. Skeletal anchorage utilizing bone plates. Aus Orthod J 1985; 9:231-233.

15. Umemori, M., J. Sugawara, H. Mitani, H. Nagasaka, and H. Kawamura. Skeletal anchorage system for open-bite correction. Am J Orthod Dentofacial Orthop 1999; 115:166-174.

16. Sherwood, K. H., J. G. Burch, and W. J. Thompson. Closing anterior open bites by intruding molars with titanium miniplate anchorage. Am J Orthod Dentofacial Orthop 2002; 122:593-600.

17. Wada, K., K. Matsushita, S. Shimazaki, Y. Miwa, Y. Hasuike, and R. Susami. An evaluation of a new case analysis of a lateral cephalometric roentgenogram. J Kanazawa Med Univ 1981; 6:60-70.

18. Miyawaki, S., I. Koyama, M. Inoue, K. Mishima, T. Sugahara, and T. Takano-Yamamoto. Factors associated with the stability of titanium screws places in the posterior region for orthodontic anchorage. Am J Orthod Dentofacial Orthop

19. Deguchi, T., T. Takano-Yamamoto, R. Kanomi, J. K. Hartsfield Jr, W. E. Roberts, and G. P. Garetto. The use of small titanium screws for orthodontic anchorage. J Dent Res 2003; 82:377-381.

20. Adell, R., U. Lekholm, B. Rockler, and P. I. Braunemark. A 15 year study of osseointegrated implants in the treatment of the edentulous jaw. Int J Oral Surg 1981; 10:387-416.

21. Hobos, S., E. Ichida, and L. T. Garcia. Osseointegration and Occlusal Rehabilitation. London, UK: Quintessence Publishing Co; $1989: 33-54$.

22. Tsunori, M., M. Mashita, and K. Kasai. Relationship between facial types and tooth and bone characteristics of the mandible obtained by CT scanning. Angle Orthod 1998; 68:557-562

23. Proffit, W. R., L. J. Bailey, C. Phillips, and T. A. Turvey. Long-term stability of surgical open-bite correction by Le Fort I osteotomy. Angle Orthod 2000; 70:112-117.

24. Hoppenreijs, T. J., H. P. Freihofer, and P. J. Stoelinga. Tuinzing DB, van't Hof MA, van der Linden FP, Nottet SJ. Skeletal and dento-alveolar stability of Le Fort I intrusion osteotomies and bimaxillary osteotomies in anterior open bite deformities. A retrospective three-centre study. Int J Oral Maxillofac Surg 1997. 26:161-175.

25. Sugawara, J. , U. B. Baik, M. Umemori , I. Takahashi , H. Nagasaka , H. Kawamura, and H. Mitani . Treatment and posttreatment dentoalveolar changes following intrusion of mandibular molars with application of a skeletal anchorage system (SAS) for open bite correction. Int J Adult Orthod Orthognath Surg 2002. 17:243-253. 